IZA DP No. 5153

Intra-household Resource Allocation: Do Parents Reduce or Reinforce Child Cognitive Ability Gaps?

Paul Frijters

David W. Johnston

Manisha Shah

Michael A. Shields

August 2010 


\title{
Intra-household Resource Allocation: Do Parents Reduce or Reinforce Child Cognitive Ability Gaps?
}

\author{
Paul Frijters \\ University of Queensland and IZA \\ David W. Johnston \\ Queensland University of Technology \\ Manisha Shah \\ University of California-Irvine and IZA \\ Michael A. Shields \\ University of Melbourne and IZA
}

Discussion Paper No. 5153

August 2010

IZA

P.O. Box 7240

53072 Bonn

Germany

Phone: +49-228-3894-0

Fax: +49-228-3894-180

E-mail: iza@iza.org

\begin{abstract}
Any opinions expressed here are those of the author(s) and not those of IZA. Research published in this series may include views on policy, but the institute itself takes no institutional policy positions.

The Institute for the Study of Labor (IZA) in Bonn is a local and virtual international research center and a place of communication between science, politics and business. IZA is an independent nonprofit organization supported by Deutsche Post Foundation. The center is associated with the University of Bonn and offers a stimulating research environment through its international network, workshops and conferences, data service, project support, research visits and doctoral program. IZA engages in (i) original and internationally competitive research in all fields of labor economics, (ii) development of policy concepts, and (iii) dissemination of research results and concepts to the interested public.
\end{abstract}

IZA Discussion Papers often represent preliminary work and are circulated to encourage discussion. Citation of such a paper should account for its provisional character. A revised version may be available directly from the author. 
IZA Discussion Paper No. 5153

August 2010

\section{ABSTRACT \\ Intra-household Resource Allocation: Do Parents Reduce or Reinforce Child Cognitive Ability Gaps?}

Do parents invest more or less in their high ability children? We provide new evidence on this question by comparing observed ability differences and observed investment differences between siblings in the NLSY. To overcome endogeneity issues we use sibling differences in handedness as an instrument for cognitive ability differences, since handedness is a strong determinant of cognitive ability. We find that parents invest more in high ability children, with a one standard deviation increase in child cognitive ability increasing parental investments by approximately one-third of a standard deviation. Consequently, differences in child cognitive ability are enhanced by differential parental investments. This finding has important implications for education policy.

JEL Classification: D13, J1

Keywords: children, cognitive ability, parental investment, handedness

Corresponding author:

Michael A. Shields

Department of Economics

University of Melbourne

Australia 3010

E-mail: mshields@unimelb.edu.au 


\section{Introduction}

Suppose there are two children in a family and their parents observe that one child is developing more slowly in terms of cognitive skills or ability, or is less healthy, relative to the other child. The question that arises is: Do parents attempt to reduce these observable differences by investing more resources, in terms of time and/or money, in the less able child or do they act to reinforce idiosyncratic endowments? Another way of posing this question is whether parents are more motivated by efficiency or equality concerns when deciding on resource allocations between their children (Becker and Tomes, 1976; Behrman et al., 1982; Rosenzweig and Schultz, 1982). The answer to this question is important because it has direct implications for the intergenerational transmission of human capital and the effectiveness of any policies aimed at reducing child inequalities (see, for example, Behrman, 1994; Altonji et al., 1997; Del Bono et al., 2008).

Even though researchers have studied this continuously for the last 30 or so years, ${ }^{1}$ there is no clear consensus on what is the dominant parental motive for within family resource allocation decisions especially with respect to childhood health endowments. Some studies find evidence of compensatory behavior, while others do not. For example, Rosenzweig and Schultz (1982) analyze parental allocation in response to differential boygirl survival data from rural India and conclude that compensating parental investment is not the dominant behavior, but rather parents act to reinforce initial differences. Behrman et al. (1982) on the other hand conclude that parents care about children's earnings inequality and tend to provide more additional resources to the less able child than is consistent with an investment model. Ayalew (2005) examines parental health and educational investment decisions using data on households in 15 villages in rural Ethiopia. The study finds that parents follow a compensatory strategy when allocating health inputs in terms of spending more on the initially unhealthier sibling; however, they act to reinforce child differences in terms of educational investment decisions. This suggests that policies aimed at reducing health inequalities are more likely to be successful than those focused on reducing

\footnotetext{
${ }^{1}$ Many empirical studies that have shed light on this topic including Griliches (1979), Rosenzweig and Schultz (1982), Rosenzweig and Wolpin (1988), Pitt et al. (1990), Behrman et al. (1994) and more recently Ayalew (2005), Del Bono et al. (2008), Datar et al., (2010) and Li et al. (2010). To control for unobserved family characteristics the literature is mostly based on samples of twins (e.g. Behrman et al., 1982; Royer, 2009; Li et al., 2010) or siblings (e.g. Rosenzweig and Wolpin, 1988; Quisumbing, 1994; Loughran et al., 2008; Datar et al., 2010), and much of the focus has been on health (such as survival rates, birthweight or weight-for-age) of children in developing countries (e.g. Rosenzweig and Schultz, 1982; Rosenzweig and Wolpin, 1988; Pitt et al., 1990). Though, some recent research has focused on health endowments in developed countries (e.g. Del Bono et al., 2008; Loughran et al., 2008; Hsin, 2009; Kelly, 2009; Royer, 2009; Datar et al., 2010). More generally, see Almond and Currie (2010) for a review of this research.
} 
educational inequalities because in the latter case parents will redistribute their own investments to counter-act equalizing public investments. ${ }^{2}$ More recently, Li et al. (2010) find evidence of multiple motivations at work in China, providing evidence of altruism, favoritism and guilt, towards the children (one of the twins) who experienced more years of rustication following Mao's mass Send-down Movement in the 1960s and 1970s. These children received higher parental transfers despite having higher earnings.

While many studies have looked at parental investments in the education and health of their children, several recent studies have focussed exclusively on health in developed countries. Datar et al. (2010) study a sample of US siblings to see if parents reinforce differences in initial health. They find that normal birth weight children are 5-11\% more likely to receive early childhood investments than their lower birth weight siblings. In contrast, Loughran et al. (2008) find that the parents in the NLSY invest more in the siblings with low birth weight. Royer (2009) finds no evidence either way, with parental investments in neonatal care not varying between twins who differed in their birth weight. Similarly, Kelly (2009), examining in-utero exposure of children in the UK National Child Development Study (a 1958 birth cohort) to the Asian influenza pandemic of 1957, finds no evidence in favor of either parental resource reinforcement or equalization.

Importantly, in the case of health investment decisions, birth weight provides a relatively 'clean' measure of initial health differences; however, there is no equivalent measure of initial cognitive ability, making endogeneity the key empirical challenge in that literature (cf. Rosenzweig and Wolpin, 1988; also see Del Bono et al., 2008 and Li et al., 2010, for detailed discussions). In particular, parental investments are very likely to have a direct effect on the cognitive ability of the child, leading to reverse causality, even at a very early age. Additionally, investments made by parents are unlikely to be independent of unobserved characteristics shared by both the parents and the child, such as genetic dispositions or a culture of learning within the family, which makes variation across households difficult to interpret. Moreover, as noted by Almond and Currie (2010), using sibling fixed effects models, while controlling for common family characteristics, does not control for the possibility that children within the family differ in unobservable ways. These issues point towards the combined use of a family fixed-effect estimator and child-specific instrumental variables as an appropriate empirical methodology, as this method is able to

\footnotetext{
${ }^{2}$ Public health investments in children typically enjoy strong returns to scale (e.g. Inoculations and massscreening) and provides services poor parents would not be able to afford, implying that public investments are likely to be able to overcome sources of health inequalities that parental spending cannot.
} 
control for reverse causality, common family unobserved characteristics and child-specific unobserved characteristics (Del Bono et al., 2008). With a good instrument the pervasive issue of measurement error is also overcome.

In this paper we make a contribution to the literature on intra-household allocation by establishing the effect of initial cognitive ability differentials on subsequent parental investments, using sibling data from the National Longitudinal Survey of Youth (NLSY). This study therefore provides a strong complement to the much larger literature that has focused on childhood health endowments. Importantly, we are able to estimate the causal effects of child cognitive ability on parental cognitive investments because of our instrumental variables within-family approach. For identification we use the finding that a child's handedness is a strong determinant of their cognitive ability, with left-handed children achieving significantly lower test scores. This are coupled with the finding that parental socioeconomic characteristics at birth have no explanatory power in predicting whether a child is born favoring their left or right-side. Child handedness therefore provides a source of random variation in child cognitive development (Frijters et al., 2009; Johnston et al., 2009, 2010; Llaurens et al., 2009). We provide evidence to support these claims.

Our main finding is consistent with the emerging economic literature on the persistence of initial differences between children: we find that a one standard deviation increase in cognitive ability increases the amount of cognitive investments by roughly one third of a standard deviation, implying that initial differences are reinforced by differential parental investments. This finding has implications for the outcome of education policy aimed at reducing inequalities in child cognitive development, because it suggests that parents could substitute investments between siblings to counteract equalizing public investments. The success therefore of public interventions depends upon whether the cognitive resources supplied by governments are of a type that parents are unable to supply themselves, and whether the cognitive resources are able to change elements of children's cognitive endowments that parents are responding to.

In Section 2 we discuss the data and descriptive statistics. Section 3 introduces our methodology and pays particular attention to the question of instrument validity. Section 4 presents the main results, and Section 5 concludes. 


\section{Data and Descriptive Statistics}

Our empirical analysis uses data from the National Longitudinal Survey of Youth (NLSY), which began with a sample of 12,686 Americans who were 14-21 years old in January 1979. The respondents were first interviewed in 1979 and were re-interviewed annually from 1979 to 1994, and biennially from 1994 to 2006. ${ }^{3}$ Importantly, in each even-numbered year since 1986 the NLSY collected detailed information, including cognitive development assessments and cognitive resource allocations, on all children born to and living with a female NLSY respondent. The child cognitive development data have been widely used in a number of different literatures (see Argys et al., 1998; Guo and Harris, 2000; James-Burdumy, 2005; and Case and Paxson, 2008) as have the cognitive resources data (see Bradley et al., 2001; Todd and Wolpin, 2007; and Cunha and Heckman, 2008).

To measure children's handedness the NLSY asks mothers about their child's hand preference when writing, brushing teeth and throwing a ball. ${ }^{4}$ Three tasks are used because there are not distinct left- and right-handed categories: most individuals reveal a hand preference for a given task, but it is not always the same hand for each task (Salmaso and Longoni, 1985). We construct a continuous measure of left-handedness by assigning a value of 0 for always right-handed, 0.25 for mostly right-handed, 0.5 for both hands, 0.75 for mostly left-handed, and 1 for always left-handed, and averaging the three responses. An alternative approach, as used by Gregg et al. (2008) for example, is to assign certain combinations of responses as signifying left-handedness, mixed-handedness and righthandedness. ${ }^{5}$ We prefer our approach as it avoids making arbitrary classifications. Furthermore, it corresponds to the theory that handedness is a continuum, with the strength of left- and right-handedness varying across people (Bryden and Steenhuis, 1991; Annett, 2002). According to our measure, roughly $80 \%$ of children are strongly right-handed (a value equal to 0 ), and roughly $5 \%$ of children are strongly left-handed (a value equal to 1 ). The mean

\footnotetext{
${ }^{3}$ The NLSY over-sampled blacks, Hispanics, low-income whites and military personnel. In our analysis, we have not excluded these over-samples. However, when the analysis is repeated using only the representative sample, similar results are obtained.

${ }^{4}$ These questions were asked in surveys between 1996 and 2006, and so children with multiple responses are allocated handedness based on their latest response (average age handedness is measured is 13). Using the latest response limits measurement error arising from the fact that a small number of children may have not fully revealed their dominant handedness at an early age.

${ }^{5}$ We also present estimates from models using a binary left-handedness indicator. They show that our main results are not sensitive to the choice of handedness measure.
} 
value of our handedness measure is 0.107 , which is consistent with the finding that around $10 \%$ of the population is mainly left-handed. ${ }^{6}$

A measure of overall cognitive ability is proxied by averaging scores on the Peabody Individual Achievement Tests (PIAT) of mathematics and reading comprehension. The PIAT of mathematics assesses early mathematic skills, such as recognizing numerals, and also more advanced concepts in geometry and trigonometry. The PIAT of reading comprehension assesses the child's ability to derive meaning from sentences that are read silently. These tests have been found to be correlated with alternative measures of cognitive ability, and each has high completion rates - see Baker et al. (1993) for a detailed discussion of each test. To aid in the interpretation of subsequent estimation results, the average test score has been transformed to have a mean of 10 and a standard deviation of one.

The NLSY quantifies the children's home environment using the Home Observation Measurement of the Environment - Short Form (HOME-SF) survey. The HOME scale was constructed by Bradley and Caldwell $(1980,1984)$ in order to assess the levels of cognitive stimulation and the levels of emotional support that children receive from their parents and their home environment. In a review, Totsika and Sylva (2004) state that "HOME is without doubt the most commonly used environmental assessment instrument in developmental research" and that "research has proved the instrument's validity in describing the home environments of children at risk and revealing the effect of home experiences in developmental outcomes.” The survey instrument includes items obtained by maternal report and interviewer observation, with the number and specific items varying by age of the child. Examples of questions on cognitive stimulation are "Do you or have you helped [your child] with the alphabet?”; “About how many children's books does your child have of his/her own?" and "How often has a family member taken or arranged to take your child to any type of museum?”. Throughout our analysis we use a log transform of the HOME cognitive stimulation and emotional support scores such that the transformed scores are increasing in stimulation and support, and have a mean of 10 and a standard deviation of one. ${ }^{7}$

Figure 1 shows the kernel density estimates of our cognitive resources index by handedness. Most interestingly, the cognitive resources received by strong left-handers are lower than the cognitive resources received by strong right-handers. Assuming that lefthandedness is exogenously determined and that there is no direct effect of handedness on

\footnotetext{
${ }^{6}$ It has been found that the proportion of people who are left-handed equals 11 percent in Canada (Bryden et al., 1997), 12 percent in the U.S. (Ruebeck et al., 2007), and 12 percent in the U.K. (Denny and O’Sullivan, 2007).

${ }^{7}$ The log transform eliminates the significant skewness in the raw index.
} 
investments, this provides evidence that in the cross-section children with lower cognitive ability receive lower cognitive resources. Figure 2 shows the distribution of differences between siblings at the same age in terms of how much cognitive resources they receive. Clearly large degrees of variation exist between siblings, with a large proportion of children receiving one standard deviation more or less cognitive resources than their siblings at the equivalent age.

The children are described by handedness in Table 1. Column 3 presents mean resources and development outcomes, and mean child and family characteristics for all children who have non-missing handedness and non-missing outcome information. ${ }^{8}$ Column 4 presents mean values for the subsample of children who have a surveyed sibling with different handedness than themself. The total number of children in the subsample equals 2,318. It is this subsample that is used to identify the impact of handedness on cognitive ability, and hence the effect of cognitive ability on resource allocation.

The table indicates that the sibling subsample is relatively similar to the full sample of children. The most significant difference between samples is the number of younger and older siblings, which is unsurprising given our sample selection requires there to be at least two siblings with different degree of handedness. There are also small differences in the proportions who have had a premature birth, a caesarean section birth, and a mother who drank during pregnancy. Mean resources and ability are also lower for the sibling subsample than for the full sample, which can be explained by the differences in household size and by the negative effect of left-handedness on cognitive ability.

Figure 3 shows the raw relationship between average cognitive ability and average cognitive resources for each percentile of the cognitive ability distribution. The graph reveals a very strong positive relationship that is almost perfectly linear (slope $=0.34$ ), except at the far left tail of the distribution where the relationship is flat, suggesting a minimal level of cognitive investment. In Section 4 we investigate whether there remains a relationship once observable and unobservable differences between children are accounted for.

\footnotetext{
${ }^{8} 453$ children with missing information for the following key control variables are omitted from the sample: caesarean section birth, birth weight, premature birth, breastfed, drank during pregnancy and smoked during pregnancy.
} 


\section{Methodology}

\subsection{Model}

Our empirical approach is based on a within family comparison of child cognitive ability and parental cognitive investments, or in other words, a family fixed-effects regression model of parental investments $(P I)$. For child $i$ in family $j$ at time $t$, we estimate:

$$
P I_{i j t}=\alpha_{j}+X_{i t} \beta+\delta C A_{i j t}+\varepsilon_{i j t}
$$

where $\alpha_{j}$ is a family fixed effect, $X_{i t}$ is a vector of characteristics that vary across children in the same family, $C A_{i j t}$ is the child's measured cognitive ability, and $\varepsilon_{i j t}$ is a random error term. The coefficient $\delta$ is the parameter of primary interest and represents the impact that cognitive ability has on parental investments. The $X_{i t}$ vector includes as many observable differences between siblings as our data allow, such as: gender, age, number of siblings, mother's age at birth, birth weight, premature birth, caesarean section birth, breastfed, and whether the mother smoked or drank during pregnancy.

Consistently estimating $\delta$ in equation (1) is complicated by the fact that cognitive ability differences between siblings are not randomly determined. Research by Cook and Evans (2000), Todd and Wolpin (2007), Cuhna and Heckman (2008), amongst others suggest that parental investments have a direct positive impact on child cognitive ability. For example, Todd and Wolpin (2007) find that racial differences in parental investments account for about $10-20 \%$ of the black-white and the Hispanic-white test score gap in math and reading. Therefore, a positive $\delta$ estimate may merely reflect the positive impact of parental investments on cognitive ability. Estimation is further complicated by the possibility of unobserved differences between siblings that are related to both ability and investments. For example, if one child is inherently more interested in intellectual activities than his or her sibling, it is likely the child will develop a superior cognitive ability as well as receive greater parental (demand-led) investments.

The strong likelihood of endogeneity bias motivates our use of an instrumental variables (IV) estimation procedure. The first-stage equation in this procedure is

$$
C A_{i j t}=\theta_{j}+X_{i t} \gamma+\lambda Z_{i}+u_{i j t}
$$


where $\theta_{j}$ is a family fixed effect, $Z_{i}$ is an instrumental variable representing the child's degree of left-handedness, and $u_{i j t}$ is a random error term. Importantly, the inclusion of the family fixed-effects in equations (1) and (2), coupled with our IV strategy, implies that identification of $\delta$ is driven by parental investment variation within families where differences in handedness has caused variation in child ability.

In addition to overcoming any endogeneity bias, our IV approach is useful for overcoming attenuation bias related to measurement error in cognitive ability. Our measure of cognitive ability comes from elaborate test score data; however, even the best test is still only a proxy for the cognitive ability that is observable to parents. Insofar as parents are likely to have superior information to the testers, measured child-development is therefore likely to suffer from random measurement error which would be overcome by of our IVspecification. The instrumentation is particularly important in the family fixed-effects specification since the attenuation bias arising from measurement error is known to be amplified if one takes out the cross-sectional information via fixed-effects. ${ }^{9}$

\subsection{Handedness and Cognitive Ability}

To legitimately use handedness as an instrument for cognitive ability, handedness must be a source of random variation that significantly affects cognitive ability but does not directly affect parental investments.

The first requirement, that handedness is strongly correlated with cognitive ability, can be easily tested. Figure 4 shows kernel density estimates of cognitive ability graphed separately for strongly left- and right-handed children. The figure reveals a sizeable difference in cognitive ability by handedness, with the left-handed distribution more negatively skewed than the right-handed distribution. In other words, left-handedness substantially raises the probability that a child will be poorly developed. Importantly, these significant ability differences are not diminished when we control for family and child characteristics. Furthermore, this is not a finding particular to children in the NLSY. Johnston et al. (2009) using Australian data, Gregg et al. (2008) using English data and Resch et al. (1997) using German data also find that left-handedness is associated with lower cognitive ability.

Figure 4 also shows that left-handedness acts upon cognitive ability in a consistent direction; it increases the probability that a child will have a low test score, but does not

\footnotetext{
${ }^{9}$ See, for example, Bound and Solon (1999) for a discussion of measurement error bias in family fixed-effects models.
} 
increase the probability that a child will have a high test score. This is an important observation, as the monotonicity assumption, which is required in a heterogeneous effect framework (Imbens and Angrist, 1994), states that while the instrument (handedness) may have no effect on some people, all of those who are affected are affected in the same way (have lower cognitive ability).

The second requirement, that handedness is exogenously determined, is supported by the literature on handedness, though it is more difficult to confirm than the requirement that it affects cognitive ability. The psychology literature proposes two main theories for the determination of handedness that are consistent with the observed differences in cognitive ability. One important theory is that handedness is genetically determined through a complex and as yet not fully understood interplay between alleles. The best known genetic theory is that handedness is determined by one gene with two alternate forms (called alleles), one dominant and one recessive, and that right-handed individuals who receive one of each allele have a cognitive advantage over left-handed individuals who receive two recessive alleles (Annett and Manning, 1989). Therefore, under this theory the lower ability of left-handers is “naturally” occurring and is not caused by parents' socioeconomic status, education, health, demographic characteristics, or behavior.

One implication of the genetic model is that mothers and fathers of left-handed children are more likely to be left-handed themselves. ${ }^{10}$ This suggests that left-handed parents may have different socioeconomic status, cognitive ability or even parenting styles than righthanded parents. Such a difference, however, is not problematic for our analysis. Our focus is on comparisons between siblings, and obviously parental socioeconomic status, cognitive ability and parenting styles is common to siblings. In other words, any unobserved parental characteristics are captured by our family fixed-effect.

The second main theory for the determination of handedness is that left-handedness is the result of exogenous factors operating on the child before or during child birth (Bakan et al. 1973). For example, an elevated incidence of left-handedness has been reported in children who have suffered severe bacterial meningitis (Ramadhani et al., 2006) and for females with early neurologic insult (Miller et al., 2005). These theories predict lower academic achievement in a sub-group of left-handers, not as a result of their hand preference per se, but because of the brain insult that caused a shift in hand preference and decreased

\footnotetext{
${ }^{10}$ Despite strong evidence for a genetic model, many left-handed parents have right-handed children, and many left-handed children have right-handed parents. For example, when both parents are left-handed only 30\% to $40 \%$ of their children are left-handed (Llaurens et al., 2009). This indicates that left-handedness is not a simple one-gene outcome for the vast majority of left-handers.
} 
cognitive ability. However, Johnston et al. (2009, 2010) test this theory by using controls for birth stress and find no strong evidence in support of it.

We investigate the possibility that handedness itself is determined by differential prenatal and immediately post-natal investments (which would invalidate handedness as an instrument) by comparing differences between siblings in their handedness and a range of characteristics that describe the pregnancy and immediate post-natal health investments (like breast feeding). The results, which are contained in Table 2, indicate that the only factor which is significantly related to handedness is gender - it is well known that boys are more likely to be left-handed. All the variables related to pre- and post-natal health are not significantly different from zero at the $5 \%$ level. In fact, using an $F$-test we are unable to reject the null hypothesis that all of the factors (apart from gender) are jointly insignificant ( $F$ $=0.93)$.

The final requirement of instrument validity is that handedness impacts upon cognitive resources only through its effect on cognitive ability. To put it another way, our instrument is invalid if parents spend more (or less) time with their left-handed children due to factors unrelated to cognitive development, because then our results would not pick up the parental reaction to initial ability differences but rather the parental reaction to other differences. The evidence on whether there are important differences between left-handers and right-handers other than cognitive development is mixed. For example, Denny and Zhang (2010) find that non-right-handedness is associated with poorer social adjustment among British children, although this effect disappears as individuals' age. Johnston et al. (2010) using US data find no difference in left-handed children's experience of poor mental health or illness, with the exception of left-handed children having a small but significantly higher probability of suffering an injury needing medical attention (perchance due to lower motor skills). In contrast, Pekkarinen at al. (2003) analyzing a sample of approximately 8,500 men and women from Finland, find no significant difference in injury involvement between left- and right-handers. Hence, if there are health differences due to handedness, they appear to be small, but we will in Section 4.2 investigate whether our results are robust to the inclusion of indicators of child health.

Another possibility is that parents spend more time with their children trying to "coax" them into right-handedness as being left-handed has traditionally been associated with cultural stigma. For example, Teng et al. (1976) observed in China a significant pressure to eat and write right-handed. Though this may still be an issue in more traditional cultures, we do not believe it is a big issue with our US data, both because of the ethnicity and year of 
birth of our surveyed children, and because we have some evidence that forced handedness in the US is infrequent. In 1998, 2137 older children from the NLSY were asked, "As a child, were you ever forced to change the hand with which you write?" Only 2.6 percent of the children replied yes. Nevertheless we re-estimate our models excluding Asian-American families and our results are robust to this potential concern. In any case though, we may note that if parents spend more time on their left-handed children in order to coax them into becoming right-handed, this would put a downward bias on our results.

\section{Results}

\subsection{Main Results}

Our main estimation results are presented in Table 3. For each specification we have restricted the sample to children with no missing information and to children with a surveyed sibling with different handedness than themselves. Moreover, each specification includes covariates representing gender, number of older and younger siblings, mother's age at birth, birth weight, premature birth, Caesarean-section birth, whether breastfed, and whether mother smoke or drank during pregnancy. Not shown, but also included in all models, are full sets of age dummies and year dummies. The covariates allow for a wide range of observable differences between siblings that may be associated with resources received.

Cross-sectional OLS estimates are reported in Column 1. The estimated cognitive ability coefficient equals 0.262 , indicating that a one standard deviation increase in cognitive ability increases cognitive resources by 0.262 standard deviations. However, this estimate is likely to be biased. It will be biased upwards if cognitive ability is positively influenced by cognitive investments, and downwards if the cognitive ability test-score measure is a noisy proxy for the cognitive ability that is observable and important to parents.

In Column 2 we present family fixed-effect estimates, in which differences in cognitive ability between children are compared to differences in cognitive resources received. This specification is similar to the fixed-effect models used by Hsin (2009) and Datar et al. (2010) in their analyses of parental investment responses to birth weight differences between siblings. The estimated cognitive ability effect is still significantly positive, but much smaller than the cross-sectional relationship. This could be due to diminished endogeneity bias or increased attenuation bias.

Before presenting our preferred IV-FE estimates, we present a reduced form analysis of cognitive resources in Column 3. We find that left-handed children receive significantly less 
resources than their right-handed siblings, suggesting that cognitive ability is positively related to cognitive resources. Column 4 presents the first-stage estimates. Handedness is strongly related to within-family differences in cognitive ability, with left-handed children scoring 0.14 standard deviations lower on our cognitive ability measure than their righthanded siblings. The associated F-statistic equals 10.96, which is unusually high for an IV model with fixed-effects. Kleibergen and Paap’s (2006) rank test for identification, which is particularly useful when employing a robust variance estimator, also suggests that the model is well identified; the Chi-squared statistic equals 11.01 and the $p$-value equals 0.0009 .

Finally, in Column 5 we present our IV-FE estimates. As explained previously, this is our most preferred specification because it is robust to reverse causality and measurement error. The estimated effect, which has a $t$-statistic of 2.14, suggests that an increase in cognitive ability by one standard deviation increases cognitive resources by 0.360 standard deviations. This estimate coincides quite closely with the raw correlation of 0.34 and is much larger than the fixed-effect estimates. An explanation for this result is that measurement error is non-trivial and is amplified in a fixed-effect model. ${ }^{11}$

A direct comparison of our results with those from other studies is not possible because to the best of our knowledge no previous study estimates the effect of child test scores on parental cognitive investments, and more generally no previous study uses an instrumental variable approach to examine the issue of intra-household resource allocation. ${ }^{12}$ The closest study to ours is Datar et al. (2010) as it represents one of the few studies that uses a direct measure of endowments; most others treat endowments as unobservable to the researcher. Datar et al. (2010) estimate a family fixed-effect model using NLSY data and find that higher birth weight children are significantly more likely than their lower birth weight siblings to be breastfed, to be taken for well-baby visits, and to receive vaccines. Interestingly, their OLS estimates are much closer to their FE estimates, suggesting that endogeneity and attenuation bias is less severe when examining the role of an at-birth endowment measure compared with a time-varying after-birth endowment measure, such as cognitive test scores.

\footnotetext{
${ }^{11}$ If we re-estimate our model without the long list of covariates (i.e. birth weight, premature birth, Caesareansection birth, whether breastfed), including only gender and the year/age dummies, we get a very similar result: the IV-FE estimate equals $0.322(t=2.06)$. This result provides extra support for our crucial assumption that handedness is exogenously determined (at least within families); because it demonstrates that our estimate is not conditional on the set of control variables used.

12 Del Bono et al. (2008) use an instrumental variable approach in their analysis of household resource allocation, but they instrument for differences in pre-natal inputs between pregnancies using as an instrument prenatal inputs during earlier pregnancies. This is a completely different approach to that used here.
} 
More generally, our finding of a strong positive relationship between cognitive ability and cognitive resources is consistent with a number of studies which find that parents reinforce endowments (for examples see Behrman et al. 1982; Rosenzweig and Wolpin 1988; Pitt et al. 1990; Behrman et al. 1994; and Datar et al. 2010). The most commonly proffered explanation for this finding is that parents are concerned with maximizing their children's future wealth and hence invest greater resources in the child for whom the marginal return to investment is highest. Importantly for this explanation, it is usually assumed that the marginal return is highest for better endowed children, which hence generates a reinforcing strategy by parents (Becker and Tomes, 1976).

\subsection{Robustness}

We now present some additional robustness tests. As discussed in Section 2, previous research has found a correlation between left-handedness and child injury rates. Though it is improbable that parents would be less likely to read to their child or help their child with homework because they have slightly more injuries than other children, a link between lefthandedness and injury rates could invalidate our identification strategy. To investigate this possibility we re-estimate our IV-FE model with additional controls for whether the child has had any illnesses or injuries requiring medical attention in the past 12 months. We find that the estimated cognitive ability effect is 0.348 (Row 1 in Table 4), which is similar to the IVFE estimate in Table 3. This finding suggests that even if left-handedness is associated with worse health outcomes, it does not impact largely upon the handedness - cognitive ability cognitive resources relationship.

In Row 2 of Table 4 we investigate the robustness of our results to our definition of handedness, by collapsing our continuous handedness measure into a binary indicator. The estimated effect changes only slightly from our headline figure (0.347 versus 0.360$)$. In Row 3 we investigate the robustness of our results to our definition of cognitive ability. The NLSY also includes: PIAT test on reading recognition, which assesses skills such as matching letters, naming names and reading single words aloud; Peabody Picture Vocabulary Test (PPVT), which assesses receptive vocabulary for Standard American English and provides a quick estimate of verbal ability and scholastic aptitude; and Memory for Digit Span Test, which assesses short-term memory. ${ }^{13}$ If we use a cognitive ability measure equal to the

\footnotetext{
${ }^{13}$ We do not use all five tests to construct our main measure of cognitive ability because children did not complete all five tests in the same years. Thus, the summary five-test measure changes in composition from year to year.
} 
average of all five test scores, the estimated effect is once again almost the same as the main finding (0.386 versus 0.360$)$.

The final row in Table 4 examines which part of the cognitive ability distribution is identifying the main effect. It might be for instance that the actual relationship is non-linear (though this is not suggested by Figure 3) and the findings are mainly due to a particular cognitive ability region. We examine the possibility of non-linearities by defining a low cognitive ability measure that equals one if the child is in the bottom $10 \%$ of test scores. The estimates show that left-handed children are 4 percentage points more likely than their righthanded siblings to have a test score in the bottom decile, and that in turn having a test score in the bottom decile means receiving around 1.3 standard deviations less cognitive resources. Therefore, it is not the case that parents compensate for very low ability.

Finally, as an interesting comparison point, we test the effect of cognitive ability on parental 'emotional' resource allocation, which is the alternative index constructed from the HOME survey. An example of a question asked to parents in relation to emotional resources is, "How many times (in the past week) have you shown [him/her] physical affection (kiss, hug, stroke hair, etc.)?”. This is interesting because the correlation between the emotional and cognitive resources measures is only 0.38 . We might expect that the allocation of emotional resources by parents should not be strongly dependent on the observed ability of the child, as emotional investments are to a larger extent likely to be a measure of the degree to which parents care about their child. Alternatively, we might view emotional resources as an investment by parents into the development of a child's non-cognitive skills. We find no significant relationship between child cognitive ability and the amount of emotional resources given by parents (results available upon request from authors). That is, parents allocate their emotional resources equally across siblings regardless of their cognitive ability.

\section{Conclusion}

A large literature, both theoretical and applied, has contributed to our understanding of the mechanisms underlying intra-household resource allocation over the last 30 years, and one key question in this research is whether or not parents allocate resources aimed at reducing endowment differentials observed between siblings, or whether they allocate more resources to the better endowed child as an investment type model would suggest (Becker and Tomes, 1976). That is, are parents driven mainly by equity or efficiency concerns? While the majority of the literature, using data from both developed and developing countries, has 
focused on parental responses to differences (both observed or indirectly measured) in sibling (or twin) health endowments, such as measured by birth weight, our contribution has been to focus on measured cognitive ability differentials between siblings observed in the NLSY. In order to overcome the well-known endogeneity issues involved in such an analysis, we have used a child's handedness as an exogenous predictor of their cognitive ability, relying on the result that left-handed children perform worse than their right-handed counterparts across a wide range of cognitive ability tests. We have shown evidence to support this hypothesis for US children, and also shown that left-handedness is not significantly predicted by other birth and development characteristics. Estimating a sibling fixed-effects model, while instrumenting for cognitive ability using child handedness, enables us to simultaneously control for both family and environment characteristics shared by all siblings and idiosyncratic characteristics or traits that differ between siblings.

We find strong evidence that parents act to reinforce observed cognitive ability differentials, with a one standard deviation increase in initial cognitive ability leading to a one-third of a standard deviation increase in cognitive resources. This is suggestive of the efficiency motive dominating the equity motive, as has been found by a number of previous papers in respect to health differences between siblings. To the extent that our measure of cognitive resources includes items that are likely to be the same across siblings (like the number of books available), this already large estimate is likely to be an underestimate of the effect of initial ability on the discretionary part of parental cognitive investments. Interestingly, while we find parental reinforce motives in the allocation of cognitive resources, we do not find this to be the case for emotional resources.

Our results suggest that estimates of the effect of cognitive ability on later life outcomes will comprise both a pure biological effect of lower initial cognitive ability and also the effect of lower parental investments. The finding that parents favor the most able child has important policy implications, where the crucial question is whether government programs are able to provide a complementary investment to that of parents (which Heckman, 2007 calls dynamic complementarities in human capital investment). If government programs aimed at improving child development offer the same type of investments that parents provide themselves, then the dominance of the efficiency motive implies parents would reduce their own levels of investments, nullifying the government program. If, however, government programs offer investments that parents are unable to provide (for instance because the care needed is too specialized), and if the investments are able to improve those cognitive endowments that parents are responding to, then the 
programs will be particularly effective as they will also stimulate parental investments. Therefore, the main policy implication of our findings is that the success of education policy depends crucially on the type of investments that are provided and how parents react to the subsequent developmental effects.

\section{References}

Almond, D and Currie, J. (2010). Human capital development before age five. NBER Working Paper no. 15827.

Altonji, J., Hayashi, F. and Kotlikoff, J. (1997). Parental altruism and inter vivos transfers: Theory and evidence. Journal of Political Economy, 105, pp. 1121-1166.

Annett, M. (2002). Handedness and Brain Asymmetry: The Right Shift Theory. Taylor \& Francis, New York.

Annett, M. and Manning, M. (1989). The disadvantage of dextrality for intelligence. British Journal of Psychology, 80, pp. 213-26.

Argys, LM., Peters HE., Brooks-Gunn J. and Smith JR. (1998). The impact of child support on cognitive outcomes of young children. Demography, 35, pp. 159-74

Ayalew, T. (2005). Parental preference, heterogeneity, and human capital inequality. Economic Development and Cultural Change, 53, pp. 381-407.

Bakan, P., Dibb, G. and Reed, P. (1973). Handedness and birth stress. Neuropsychologia,11, pp. 363-66.

Baker, PC., Keck, CK., Mott, FL. and Quinlan, SV. (1993). NLSY Child Handbook. Center for Human Resource Research, Ohio State University.

Becker, G. and Tomes, N. (1976). Child endowments and the quantity and quality of children. Journal of Political Economy, 84, pp. S143-S162.

Behrman, JR., Pollak, RA. and Taubman, P. (1982). Parental preferences and provision for progeny. Journal of Political Economy, 90, pp. 52-73.

Behrman, JR., Rosenzweig, MR. and Taubman, P. (1994). Endowments and the allocation of schooling in the family and in the marriage market: The twins experiment. Journal of Political Economy, 102, pp. 1131-1174.

Bound, J. and Solon, G. (1999). Double trouble: On the value of twins-based estimation of the return to schooling. Economics of Education Review, 18, pp. 169-182.

Bradley, RH. and Caldwell BM. (1980). The relation of home environment, cognitive competence, and IQ among males and females. Child Development, 51, pp. 1140-1148.

Bradley, RH. and Caldwell BM. (1984). The relation of infants' home environments to achievement test performance in first grade: A follow-up study. Child Development, 55, pp. 803-809.

Bradley, RH., Corwyn, RF., McAdoo, HP. and Coll, CG. (2001). The home environments of children in the United States Part I: Variations by age, ethnicity, and poverty status. Child Development, 72, pp. 1844-1867.

Bryden, MP. and Steenhuis, RE. (1991). Issues in the assessment of handedness. In Kitterle FL. (ed.) Cerebral Laterality. Hillsdale, NJ: Lawrence Erlbaum Associates; pp. 35-51.

Bryden, MP., Roy EA., McManus IC., and Bulman-Fleming MB. (1997). On the genetics and measurement of human handedness. Laterality, 2, pp. 317-36.

Case, A. and Paxson, C. (2008). Stature and status: Height, ability, and labor market outcomes. Journal of Political Economy, 116, pp. 499-532.

Cook, MD. and Evans, WN. (2000). Families or schools? Explaining the convergence in white and black academic performance. Journal of Labor Economics, 8, pp. 729-753. 
Cunha, F. and Heckman, JJ. (2008). Formulating, identifying and estimating the technology of cognitive and noncognitive skill formation. Journal of Human Resources, 43, pp. 738-782.

Datar, A., Kilburn, RM. and Loughran, DS. (2010). Endowments and parental investments in infancy and early childhood. Demography, 47, pp. 145-162.

Del Bono, E., Ermisch, J. and Francesconi, M. (2008). Intrafamily resource allocations: A dynamic model of birth weight. IZA Discussion Papers no. 3704, Institute for the Study of Labor (IZA), Bonn.

Denny, K. and O'Sullivan, V. (2007). The economic consequences of being left-handed: Some sinister results. Journal of Human Resources, 42, pp. 353-374.

Denny, K. and Zhang, W. (2010). In praise of ambidexterity: How a continuum of handedness predicts social adjustment. UCD Working Paper, Dublin.

Frijters, P., Johnson, DW., Shah, M., Shields, MA. (2009). To work or not to work? Maternal labor supply and child development. American Economic Journal: Applied Economics, 1, pp. 97-110.

Gregg, P., Janke, K. and Propper C. (2008). Handedness and child development. CMPO Working Paper No. 08/198, University of Bristol.

Griliches, Z. (1979). Sibling models and data in economics: Beginnings of a survey. Journal of Political Economy, 87, pp. S37-S64,

Guo, G., and Harris, KM. (2000). The mechanisms mediating the effects of poverty on children's intellectual development. Demography, 37, pp. 431-447.

Heckman, JJ. (2007). The economics, technology, and neuroscience of human capability formation. Proceedings of the National Academy of Sciences, 104(33): 13250-55.

Hsin, A. (2009). Is biology destiny? Birth weight and differential parental treatment. Manuscript, Population Studies Center, University of Michigan.

Imbens, G. and Joshua A. (1994). Identification and estimation of local average treatment effects. Econometrica, 62, pp. 467-476.

James-Burdumy, S. (2005). The effect of maternal labor force participation on child development. Journal of Labor Economics, 23, pp. 177-211.

Johnston, DW., Nicholls, M., Shah, M. and Shields, MA. (2009). Nature's experiment? Handedness and early childhood development. Demography, 46, pp. 281-301.

Johnston, DW., Nicholls, M., Shah, M. and Shields, MA. (2010). Handedness, health and cognitive development: Evidence from children in the NLSY. IZA Discussion Papers 4774, Institute for the Study of Labor (IZA), Bonn.

Kelly, E. (2009). The scourge of Asian Flu: in utero exposure to pandemic influenza and the development of a cohort of British children. Discussion Paper 0917, Institute for Fiscal Studies, London.

Kleibergen, F. and R. Paap (2006). Generalized Reduced Rank Tests Using the Singular Value Decomposition, Journal of Econometrics, 127, pp. 97-126.

Li, H., Rosenzweig, M. and Zhang, J. (2010). Altruism, favoritism and guilt in the allocation of family resources: Sophie's choice in Mao's mass send-down movement. Journal of Political Economy, 118, pp. 1-38.

Llaurens, V., Raymond, M. And Faurie, C. (2009). Why are some people left-handed? An evolutionary perspective. Philosophical Transactions of the Royal Society (B), 364, pp. 881-894.

Loughran, DS., Datar, A. and Kilburn, MR. (2008). The response of household parental investment to child endowments. Review of the Economics of the Household, 6, pp. 223-242. 
Miller, JW., Jayadev, S., Dodrill, CB. and Ojemann, GA. (2005). Gender differences in handedness and speech lateralization related to early neurologic insults. Neurology, 65, pp. 1974-75.

Pekkarinen, A., Salminen, S. and Jarvelin, MR. (2003). Hand preference and risk of injury among the Northern Finland birth cohort at the age of 30. Laterality, 8, pp. 339-346

Pitt, MM., Rosenzweig, MR. and Hassan, MH. (1990). Productivity, health, and inequality in the intra-household distribution of food in low-income countries. American Economic Review, 80, pp. 1139-56.

Quisumbing, AR. (1994). Intergenerational transfers in Philippine rice villages. Journal of Development Economics, 43, pp. 167-195.

Ramadhani, M., Koomen, I., Grobbee, D., van Donselaar, C., van Furth, AM. and Uiterwaal, C. (2006). Increased occurrence of left-handedness after severe childhood Bacterial Meningitis: Support for the pathological left-handedness hypothesis. Neuropsychologia, 44, pp. 2526-32.

Resch, F, Haffner, J., Parzer, P., Pfueller, U., Strehlow, U and Zerahn-Hartung, C. (1997). Testing the hypothesis of the relationships between laterality and ability according to Annett's right-shift theory: Findings in an epidemiological sample of young adults. British Journal of Psychology, 88, pp. 621-6.

Rosenzweig, MR. and Schultz, TP. (1982). Market opportunities, genetic endowments, and intrafamily resource distribution: Child survival in rural India. American Economic Review, 72, pp. 803-15.

Rosenzweig, MR. and Wolpin, KI. (1988). Heterogeneity, intrafamily distribution, and child health. Journal of Human Resources, 23, pp. 437-461.

Royer, H. (2009). Separated at girth: US twin estimates of the effects of birth weight. American Economic Journal: Applied Economics, 1, pp. 49-85.

Ruebeck, CS., Harrington Jr. JE. and Moffitt, R. (2007). Handedness and earnings. Laterality, 12, pp. 101-20.

Salmaso, D. and Longoni, AM. (1985). Problems in the assessment of hand preference. Cortex, 22, pp. 533-549.

Teng, E.L., Lee, P.H., Yang, K.S. and Chang P.C. (1976). Handedness in a Chinese population: Biological, social, and pathological factors. Science, 193, pp. 1148-1150.

Todd, P and K. Wolpin (2007). The production of cognitive achievement in children: Home, school, and racial test score gaps. Journal of Human Capital, 1, pp. 91-136.

Totsika,V. and Sylva, K. (2004). The Home Observation for Measurement of the Environment revisited. Child and Adolescent Mental Health, 9, pp. 25-35. 
Figure 1: Density Estimates of Left- and Right-handed Children’s Cognitive Resources

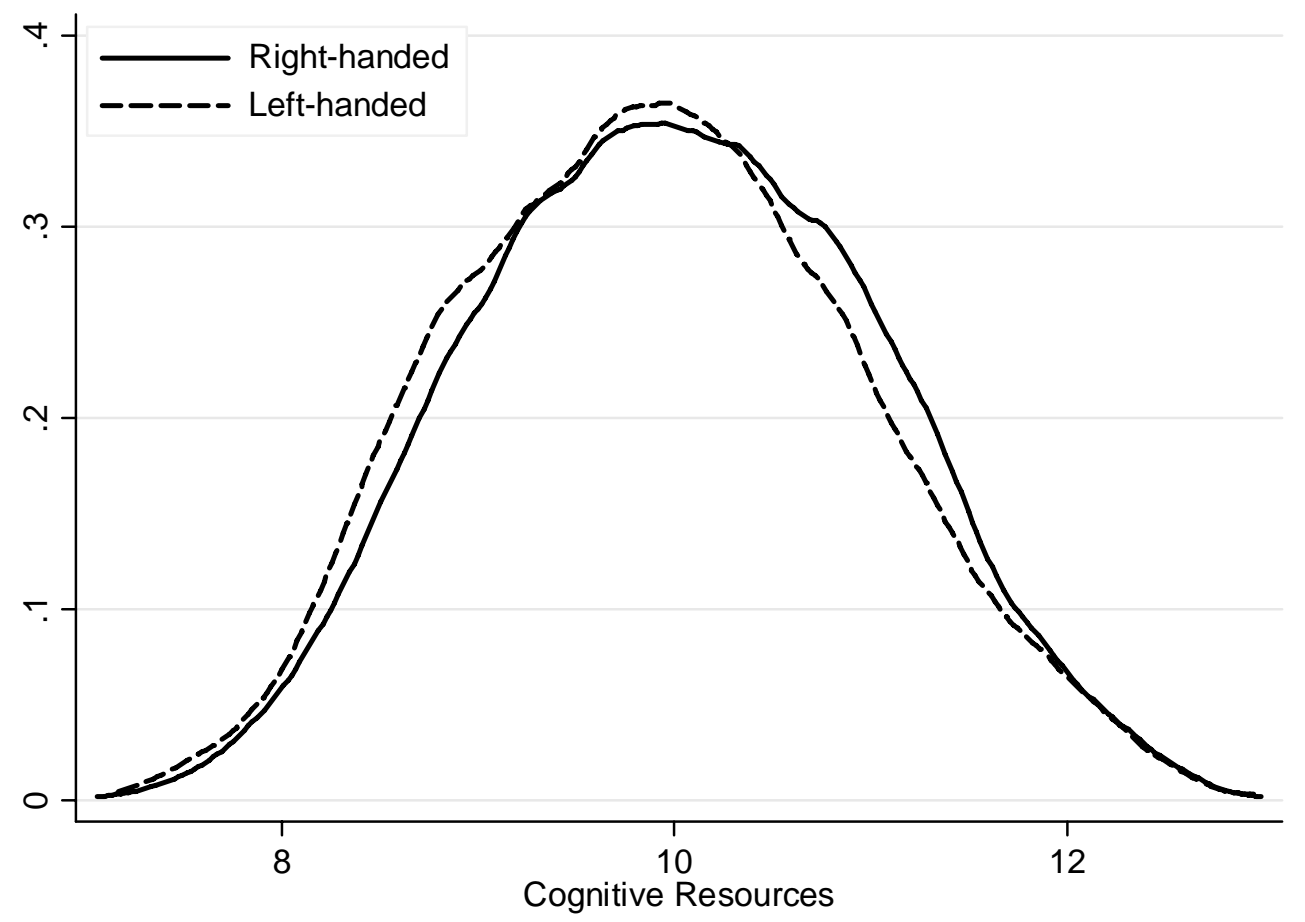

Figure 2: Differences in Cognitive Resources that Siblings Received at the same Age

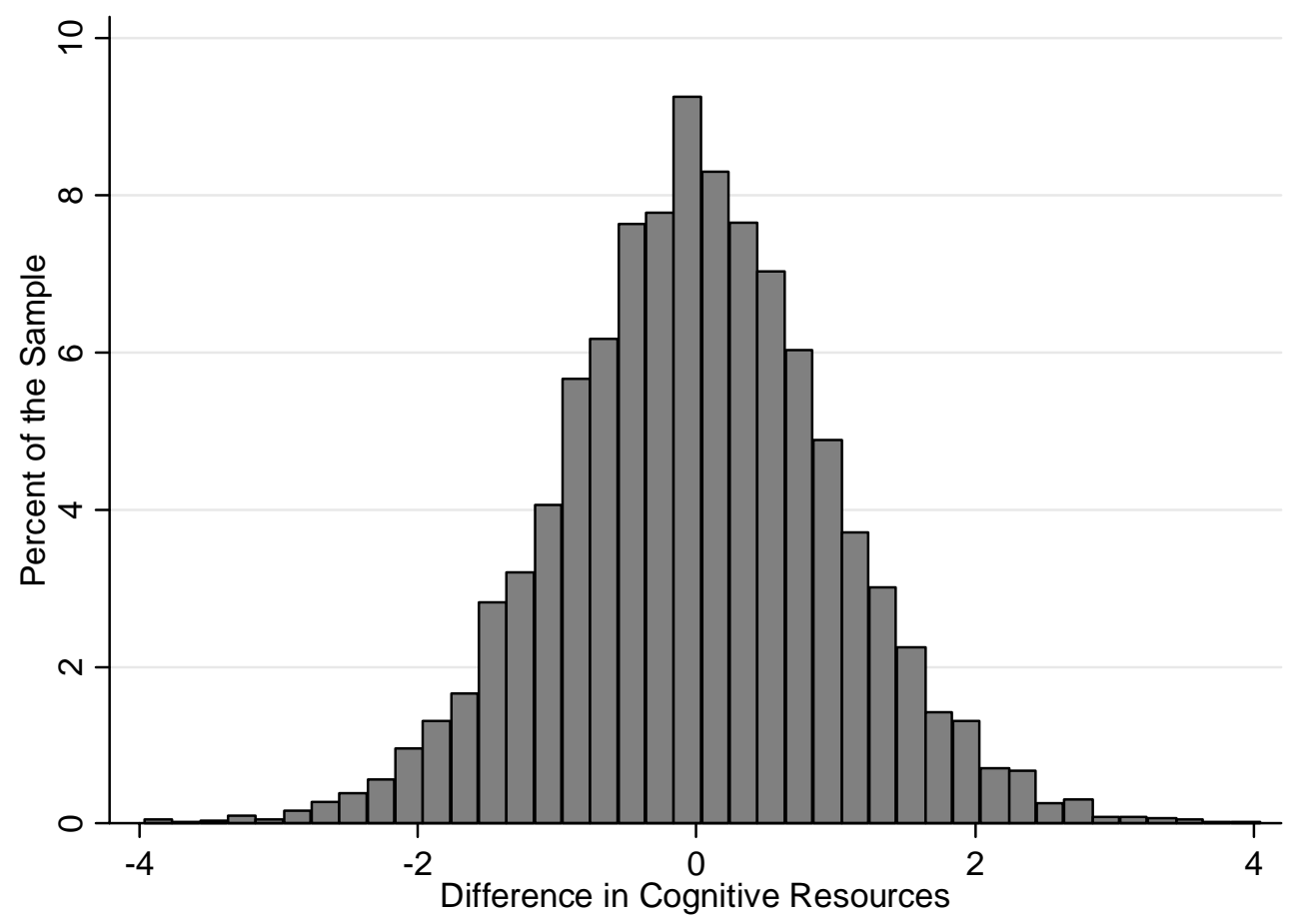


Figure 3: Mean Cognitive Resources and Cognitive Ability for each Percentile of the Cognitive Ability Distribution

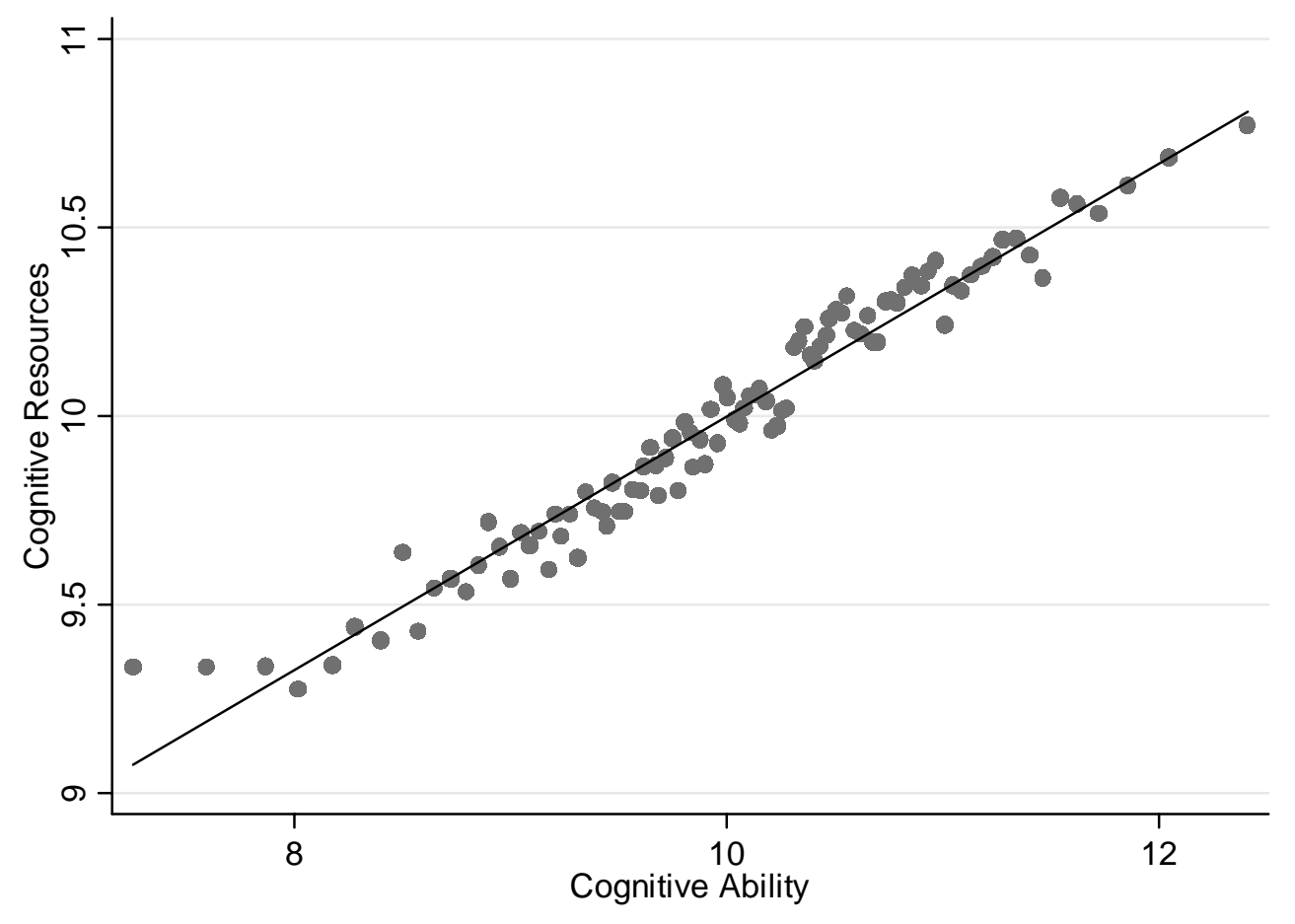

Figure 4: Density Estimates of Left- and Right-handed Children's Cognitive Ability

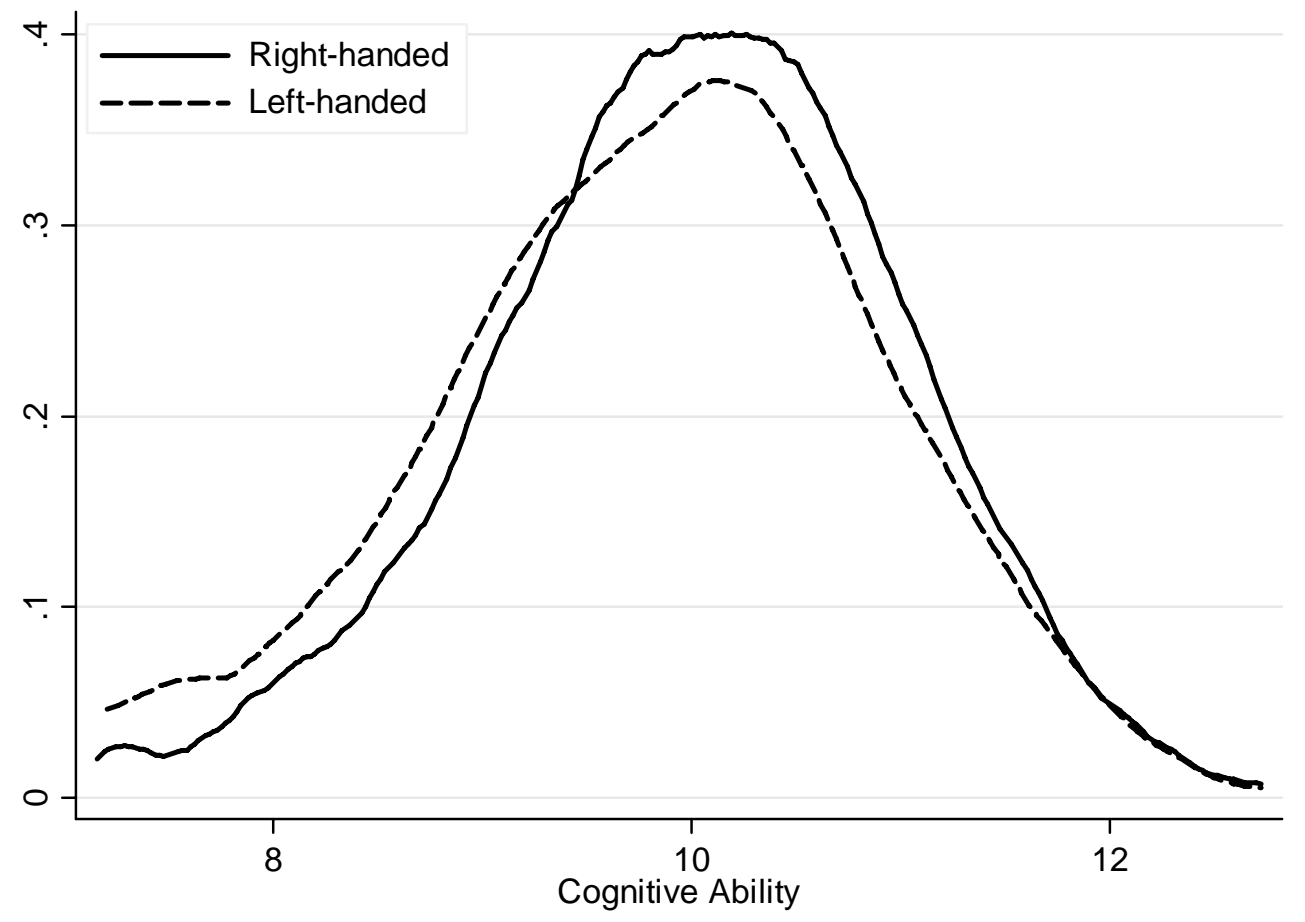


Table 1: Definitions and Sample Means of Key Variables

\begin{tabular}{l|l|cc}
\hline \multicolumn{1}{c|}{$\begin{array}{c}\text { Variables } \\
\text { (1) }\end{array}$} & \multicolumn{1}{c|}{\begin{tabular}{c}
\multicolumn{1}{c}{$\begin{array}{c}\text { Fefinition } \\
\text { (2) }\end{array}$} \\
\multicolumn{1}{c}{ Sumple } \\
(3)
\end{tabular}} & $\begin{array}{c}\text { Sibling } \\
\text { Sub-Sample } \\
\text { (4) }\end{array}$ \\
\hline Cognitive resources & Transformed HOME-SF cognitive resources index & 10.00 & 9.931 \\
Cognitive ability & Mean test score & 10.00 & 9.896 \\
Left-handedness & Index ranges from 0 (always right) to 1 (always left) & 0.107 & 0.250 \\
\hline Male & Child is male (dv) & 0.508 & 0.506 \\
Age & Child's age & 9.198 & 9.248 \\
Number of older siblings & Number of older siblings residing in the household & 0.899 & 1.135 \\
Number of younger siblings & Number of younger siblings residing in the household & 0.869 & 1.040 \\
Low birth weight & Birth weight < 2500 grams (dv) & 0.079 & 0.090 \\
Premature birth & Born before 37 weeks of gestation (dv) & 0.122 & 0.134 \\
Caesarean section birth & Born via a Caesarean section (dv) & 0.221 & 0.189 \\
Mother's age at birth & Mother's age at birth & 25.51 & 25.05 \\
Breastfed & Breastfed for at least one week (dv) & 0.457 & 0.428 \\
Smoked during pregnancy & Mother smoked during pregnancy (dv) & 0.265 & 0.295 \\
Drank during pregnancy & Mother drank during pregnancy (dv) & 0.308 & 0.299 \\
Worked during pregnancy & Mother worked during pregnancy (dv) & 0.586 & 0.527 \\
Year of birth & Year child was born & 1986.0 & 1985.5 \\
\hline
\end{tabular}

Notes: There are 6593 children from 3281 households in the full sample, and 2318 children from 852 households in the sibling sample. Sibling sample includes only those children who have a sibling with different handedness than themselves. Mean resources, ability, age and number of siblings are averages across children and time, all other variables are time invariant. The abbreviation $\mathrm{dv}$ denotes a dummy variable. 
Table 2: Family Fixed-Effect Regression Model of Child Handedness

\begin{tabular}{lcc}
\hline & Coef. & Std. Error \\
\hline Male & $0.094^{* *}$ & $(0.021)$ \\
Number of older siblings & -0.014 & $(0.017)$ \\
Low birth weight & 0.053 & $(0.048)$ \\
Premature birth & 0.004 & $(0.042)$ \\
Caesarean section birth & 0.050 & $(0.057)$ \\
Mother's age at birth & 0.003 & $(0.021)$ \\
Breastfed & -0.006 & $(0.034)$ \\
Smoked during pregnancy & -0.079 & $(0.041)$ \\
Drank during pregnancy & 0.059 & $(0.031)$ \\
Worked during pregnancy & 0.000 & $(0.028)$ \\
Year of birth & -0.000 & $(0.021)$ \\
\hline Number of children & 2318 & \\
\hline
\end{tabular}

Note: Dependent variable is measure of left-handedness and ranges from 0 to 1 . Standard errors are clustered at the family level. * and ** denote significance at .05 and .01 levels. Sample includes only those children who have an observed sibling with different handedness than themselves. $F$-statistic for joint significance of non-gender covariates equals 0.93 . 
Table 3: Regression Models of Cognitive Ability and Cognitive Resources

\begin{tabular}{|c|c|c|c|c|c|}
\hline & $\begin{array}{c}\text { Cognitive } \\
\text { Resources } \\
\text { (OLS) } \\
(1)\end{array}$ & $\begin{array}{c}\text { Cognitive } \\
\text { Resources } \\
\text { (FE) } \\
\text { (2) }\end{array}$ & $\begin{array}{c}\text { Cognitive } \\
\text { Resources } \\
\text { (FE) } \\
\text { (3) }\end{array}$ & $\begin{array}{c}\text { Cognitive } \\
\text { Ability } \\
\text { (FE) } \\
\text { (4) }\end{array}$ & $\begin{array}{c}\text { Cognitive } \\
\text { Resources } \\
\text { (IV-FE) } \\
(5)\end{array}$ \\
\hline Cognitive Ability & $\begin{array}{l}0.262^{* *} \\
(0.017)\end{array}$ & $\begin{array}{l}0.067^{* *} \\
(0.011)\end{array}$ & & & $\begin{array}{c}0.360^{*} \\
(0.168)\end{array}$ \\
\hline Left-handedness & & & $\begin{array}{l}-0.051^{*} \\
(0.021)\end{array}$ & $\begin{array}{c}-0.141^{* *} \\
(0.043)\end{array}$ & \\
\hline Male & $\begin{array}{c}-0.095^{* *} \\
(0.032)\end{array}$ & $\begin{array}{c}-0.109^{* *} \\
(0.018)\end{array}$ & $\begin{array}{c}-0.108^{* *} \\
(0.018)\end{array}$ & $\begin{array}{l}-0.047 \\
(0.033)\end{array}$ & $\begin{array}{c}-0.091^{* *} \\
(0.022)\end{array}$ \\
\hline Number of older siblings & $\begin{array}{c}-0.155^{* *} \\
(0.025)\end{array}$ & $\begin{array}{c}-0.090^{* *} \\
(0.034)\end{array}$ & $\begin{array}{c}-0.095^{* *} \\
(0.035)\end{array}$ & $\begin{array}{l}-0.083 \\
(0.048)\end{array}$ & $\begin{array}{c}-0.065 \\
(0.036)\end{array}$ \\
\hline Number of younger siblings & $\begin{array}{l}-0.051^{*} \\
(0.024)\end{array}$ & $\begin{array}{l}-0.026 \\
(0.027)\end{array}$ & $\begin{array}{l}-0.030 \\
(0.028)\end{array}$ & $\begin{array}{c}-0.055 \\
(0.035)\end{array}$ & $\begin{array}{l}-0.010 \\
(0.027)\end{array}$ \\
\hline Low birth weight & $\begin{array}{c}0.015 \\
(0.074)\end{array}$ & $\begin{array}{c}0.028 \\
(0.041)\end{array}$ & $\begin{array}{c}0.030 \\
(0.042)\end{array}$ & $\begin{array}{c}-0.004 \\
(0.074)\end{array}$ & $\begin{array}{c}0.031 \\
(0.043)\end{array}$ \\
\hline Premature birth & $\begin{array}{c}0.052 \\
(0.066)\end{array}$ & $\begin{array}{l}-0.038 \\
(0.032)\end{array}$ & $\begin{array}{l}-0.048 \\
(0.032)\end{array}$ & $\begin{array}{l}-0.141^{*} \\
(0.065)\end{array}$ & $\begin{array}{c}0.003 \\
(0.044)\end{array}$ \\
\hline Caesarean section birth & $\begin{array}{l}-0.078 \\
(0.056)\end{array}$ & $\begin{array}{c}0.012 \\
(0.040)\end{array}$ & $\begin{array}{c}0.004 \\
(0.042)\end{array}$ & $\begin{array}{c}-0.168 \\
(0.090)\end{array}$ & $\begin{array}{c}0.064 \\
(0.054)\end{array}$ \\
\hline Mother's age at birth & $\begin{array}{l}0.056^{* * *} \\
(0.012)\end{array}$ & $\begin{array}{l}-0.043 \\
(0.035)\end{array}$ & $\begin{array}{c}-0.046 \\
(0.035)\end{array}$ & $\begin{array}{l}-0.052 \\
(0.036)\end{array}$ & $\begin{array}{c}-0.027 \\
(0.038)\end{array}$ \\
\hline Breastfed & $\begin{array}{l}0.195^{* *} \\
(0.042)\end{array}$ & $\begin{array}{l}-0.055 \\
(0.029)\end{array}$ & $\begin{array}{c}-0.054 \\
(0.030)\end{array}$ & $\begin{array}{c}0.041 \\
(0.052)\end{array}$ & $\begin{array}{l}-0.069^{*} \\
(0.031)\end{array}$ \\
\hline Smoked during pregnancy & $\begin{array}{c}-0.139^{* *} \\
(0.048)\end{array}$ & $\begin{array}{l}-0.055 \\
(0.042)\end{array}$ & $\begin{array}{c}-0.056 \\
(0.043)\end{array}$ & $\begin{array}{c}0.026 \\
(0.075)\end{array}$ & $\begin{array}{l}-0.065 \\
(0.045)\end{array}$ \\
\hline Drank during pregnancy & $\begin{array}{l}-0.071 \\
(0.043)\end{array}$ & $\begin{array}{c}0.009 \\
(0.024)\end{array}$ & $\begin{array}{c}0.009 \\
(0.024)\end{array}$ & $\begin{array}{c}-0.036 \\
(0.047)\end{array}$ & $\begin{array}{c}0.022 \\
(0.026)\end{array}$ \\
\hline Worked during pregnancy & $\begin{array}{l}0.241^{* *} \\
(0.040)\end{array}$ & $\begin{array}{c}0.011 \\
(0.025)\end{array}$ & $\begin{array}{c}0.017 \\
(0.025)\end{array}$ & $\begin{array}{c}0.091^{*} \\
(0.045)\end{array}$ & $\begin{array}{l}-0.015 \\
(0.031)\end{array}$ \\
\hline Observations & 8474 & 8474 & 8474 & 8474 & 8474 \\
\hline
\end{tabular}

Note: FE models include family-fixed effects. Full sets of age and year dummies are included in each model but are not shown. Standard errors clustered at the family level are shown in parentheses. ${ }^{*}$ and ${ }^{* *}$ denote significance at .05 and .01 levels. Sample includes only those children who have an observed sibling with different handedness than themselves. The left-handedness instrument ranges from 0 strongly right-handed to 1 strongly left-handed. F-statistic on left-handedness in the first-stage equation equals 10.96 . 
Table 4: Robustness Regression Models

\begin{tabular}{|c|c|c|}
\hline Model Variations & $\begin{array}{c}\text { First-Stage: } \\
\text { Effect of handedness } \\
\text { on ability }\end{array}$ & $\begin{array}{c}\text { Second-Stage: } \\
\text { Effect of ability on } \\
\text { resources }\end{array}$ \\
\hline (1) Add illness and injury covariates & $\begin{array}{c}-0.143^{* *} \\
(0.043)\end{array}$ & $\begin{array}{c}0.348^{*} \\
(0.164)\end{array}$ \\
\hline (2) Binary measure of left-handedness & $\begin{array}{c}-0.127^{* *} \\
(0.038)\end{array}$ & $\begin{array}{c}0.347^{*} \\
(0.164)\end{array}$ \\
\hline (3) Cognitive ability measure using 5 tests & $\begin{array}{c}-0.132^{* * *} \\
(0.043)\end{array}$ & $\begin{array}{c}0.386^{*} \\
(0.184)\end{array}$ \\
\hline (4) Binary cognitive ability measure & $\begin{array}{l}0.040^{* *} \\
(0.014)\end{array}$ & $\begin{array}{l}-1.255^{*} \\
(0.633)\end{array}$ \\
\hline
\end{tabular}

Note: All figures from FE regressions that include the controls used in Table 2. Sample size equals 8474 in all regressions. Standard errors clustered at the family level are shown in parentheses. * and ** denote significance at .05 and .01 levels. Row 1 includes two indicators for whether child had illness/injury in past 12 months requiring medical treatment. Row 2 uses a handedness measure equaling one if handedness score is $\geq 0.5$ ( $10.5 \%$ of children). Row 3 uses an ability measure equaling average of scores in PPVT test, three PIAT tests and memory digit span test. Row 4 uses an ability measure equaling one if score is in bottom $10 \%$ and zero otherwise. 